\title{
Pathological alteration in the choroid plexus of Alzheimer's disease: implication for new therapy approaches
}

\author{
Agnieszka Krzyzanowska ${ }^{1,2}$ and Eva Carro ${ }^{1,2 *}$ \\ ${ }^{1}$ Neuroscience Group, Instituto de Investigacion Hospital 12 de Octubre (i+12), Madrid, Spain \\ ${ }^{2}$ Biomedical Research Networking Center in Neurodegenerative Diseases, Madrid, Spain
}

Edited by:

Joana A. Palha, University of Minho, Portugal

Reviewed by:

Jason B. Wu, Cedars-Sinai Medical Center, USA

Catarina Oliveira, CNC-Center for

Neuroscience, Portugal

${ }^{*}$ Correspondence:

Eva Carro, Neuroscience Group, Instituto de Investigacion Hospital 12 de Octubre (i+12), Avenue de

Córdoba s/n, 28041 Madrid, Spain

e-mail: carroeva@h120.es
Morphological alterations of choroid plexus in Alzheimer's disease (AD) have been extensively investigated. These changes include epithelial atrophy, thickening of the basement membrane, and stroma fibrosis. As a result, synthesis, secretory, and transportation functions are significantly altered resulting in decreased cerebrospinal fluid (CSF) turnover. Recent studies discuss the potential impacts of these changes, including the possibility of reduced resistance to stress insults and slow clearance of toxic compounds from CSF with specific reference to the amyloid peptide. Here, we review new evidences for AD-related changes in the choroid plexus. The data suggest that the significantly altered functions of the choroid plexus contribute to the multiparametric pathogenesis of late-onset AD.

Keywords: choroid plexus, Alzheimer's disease, amyloid, mitochondria, cell death, oxidative stress

\section{INTRODUCTION}

In the recent years, much attention has been directed to the roles of the choroid plexus in the central nervous system (CNS) under both normal and pathological conditions. This specialized ventricular structure has recently emerged as a key player in a variety of processes that monitor and maintain the biochemical and cellular homeostasis of the CNS.

The main role of the choroid plexus is to produce cerebrospinal fluid (CSF) and to maintain the extracellular environment of the brain by monitoring the chemical exchange between the CSF and the brain tissue. This involves the surveying of the chemical and immunological status of the extracellular fluid and the removal of toxic substances as well as important roles in the regenerative processes following traumatic events. In addition to CSF, the plexus produces various peptides which can have nourishing and neuroprotective properties.

The choroid plexus is subject to various external factors and undergoes structural and physiological changes during aging and disease states. Detrimental changes in the choroid plexus anatomy, function, and CSF turnover have been found in several neurological diseases, including Alzheimer's disease (AD; Serot et al., 1997, 2000, 2003; Preston, 2001; Stopa et al., 2001; Emerich et al., 2004; Alvira-Botero and Carro, 2010). In the present review we present and summarize the recent findings on pathogenic processes occurring within the choroid plexus and discuss their direct and indirect effects on the mechanisms of $\mathrm{AD}$.

\section{CHOROID PLEXUS IN AD PATIENTS}

Alzheimer's disease is characterized by the production and accumulation of $\beta$-amyloid (A $\beta$ ) species in the form of oligomers, fibrils, and large aggregates called $\mathrm{A} \beta$ deposits leading to classical senile plaques in the brain, and vascular deposits (amyloid angiopathy) in brain and meningeal blood vessels (Gentile et al., 2004). Recent advances have led to a better understanding of the cellular and molecular pathways of AD. Although amyloid cascade theory as the primary cause of the disease is actually a controversy, pathological mechanisms in this cascade involve neurotoxic effects of amyloid peptides probably producing oxidative damage and apoptosis in brain cells, including choroid plexus epithelial cells (Perez-Gracia et al., 2009; Vargas et al., 2010b). However, there are alternative proposed processes or hypotheses which might be involved in pathological development of AD.

Recently, emphasis has focused on comorbidity of $\mathrm{AD}$ and the deficient clearance of $A \beta$ across the blood-brain barrier (BBB; Deane et al., 2004; Tanzi et al., 2004; Zlokovic, 2004) and the blood-CSF barrier (BCSFB; Zlokovic et al., 1996). The traditional role ascribed to the choroid plexus has been to provide physical protection to the brain and to facilitate removal of brain metabolites through bulk drainage of CSF. However, recent studies suggest that the choroid plexus-CSF system plays a much more active role in AD (Weller, 1998; Stopa et al., 2001; Carro et al., 2006; Maurizi, 2010; Vargas et al., 2010b).

The choroid plexus is subject to morphological and physiological changes that produce a wide range of effects. In $\mathrm{AD}$ the choroid plexus develops abnormalities similar to those observed with aging, although greatly enhanced. Epithelial atrophy is significantly accentuated: a decrease in cell height is observed compared to age-matched controls (Serot et al., 2000). Epithelial cells acquire numerous lipofuscin vacuoles and Biondi bodies increase significantly in AD patients (Miklossy et al., 1998; Wen et al., 1999; Alvira-Botero and Carro, 2010). These modifications could alter choroid plexus functions, including synthesis, secretion, and transport of proteins and other molecules. Although this is not enough to cause amyloid deposits in the majority of AD cases, the authors consider the condition of the choroid plexus an important factor in the initiation and development of $\mathrm{AD}$ pathology. Moreover, the authors hypothesize that disrupted choroid plexus functions may precede several AD hallmarks, including amyloid brain accumulation. In the authors' view, altered choroid plexus functions may be, at least, one of the primary pathogenic events in late-onset $\mathrm{AD}$ 
(Figure 1). Multifactorial changes, including genetic and environmental alterations, result in a number of common mechanisms of degeneration, such as mitochondrial dysfunction, oxidative stress, calcium homeostasis dysregulation, and a global decrease of functional choroid plexus.

\section{A $\beta$ DEPOSITS}

The appearance of neurofibrillary tangles and extracellular senile plaque deposition, whose major constituent is $\mathrm{A} \beta$, are the main hallmarks of AD (Selkoe, 2000a,b). Besides accumulating in brain parenchyma and blood vessels, $A \beta$ also accumulates in choroid plexus (Dietrich et al., 2008). Several data have shown pathological argyrophilic filaments with histochemical properties of amyloid showing striking morphological similarity to curly fibers and/or tangles accumulating in epithelial cells of choroid plexus (Reusche, 1997; Miklossy et al., 1998, 1999; Wen et al., 1999). Recent results from our group revealed the presence of $A \beta$ deposits in the choroid plexus in autopsy material from $A D$ patients, and suggest a direct relationship between $A \beta$ deposits at choroid plexus epithelium and the development of a functional and structural disruption of the organ (Dietrich et al., 2008).

Soluble $A \beta$, a product of the secretory pathway in amyloid precursor protein (APP) processing, is produced by the choroid plexus as observed in both rat and human post-mortem tissue (Kalaria et al., 1996). APP is synthesized also by many cells outside the $\mathrm{CNS}$ and deposition of $\mathrm{A} \beta$ protein was reported to occur in nonneuronal tissues (Biewend et al., 2006). As shown in Figure 2, $\mathrm{A} \beta$ immunoreactivity is detected in choroid plexus epithelial cells from non-demented subjects, but the proportion of epithelial cells containing $A \beta$ accumulation increases significantly in choroid plexus from AD patients (Figure 2). The authors suggest that $\mathrm{A} \beta$ probably accumulates in the choroid plexus secondary to a dysfunction and a pathological cascade as illustrated in Figure 1.

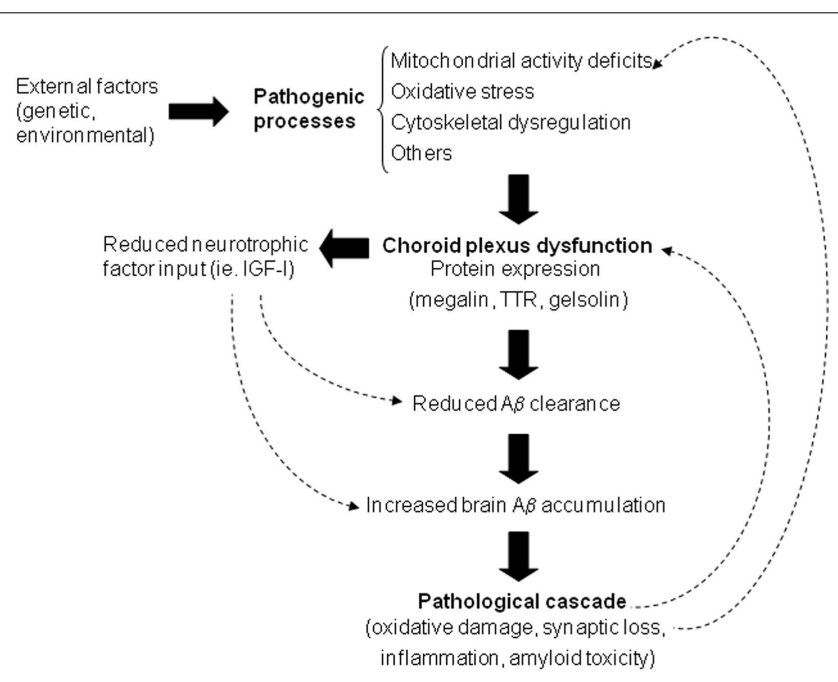

FIGURE 1 | Proposed sequence of pathological processes involved in Alzheimer's disease. Various pathogenic processes contribute to the dysfunction of the choroid plexus which results in impaired $A \beta$ processing. This and the resultant accumulation of $A \beta$ can in turn feed back to enhance the pathogenic processes.
The deficits in mitochondrial activity, increase in oxidative stress together with above mentioned morphological changes which are observed in $\mathrm{AD}$, are likely to lead not only to abnormal brain $\mathrm{A} \beta$ clearance at the $\mathrm{BCSFB}$, but also increased or defective $\mathrm{A} \beta$ processing from APP, which has been described in choroid plexus (Kalaria et al., 1996; Premkumar and Kalaria, 1996) and would contribute to the development of $A \beta$ accumulation in this tissue.

\section{MITOCHONDRIAL ACTIVITY}

Mitochondrial dysfunction is one of the earliest deficits identified in AD brains (Valla et al., 2001; Beal, 2005; Manczak et al., 2006). It has been described that mitochondrial enzyme activity defects occur in hippocampal neurons and choroidal epithelial cells more frequently in AD patients (Cottrell et al., 2001). Increase in the number of COX-deficient choroid epithelial cells provides strong evidence that a substantial mitochondrial enzyme activity decline occurs in individual cells more frequently in $\mathrm{AD}$ than in normal aging, This deficiency in mitochondrial enzyme activity is likely to result in a decrease in transport across the epithelial calls and thus has implications in choroidal $A \beta$ clearance, highlighting the role of mitochondria in the pathogenesis of $\mathrm{AD}$.

On the other hand, several studies indicate that $A \beta$ itself can impair mitochondrial function (Canevari et al., 1999; Casley et al., $2002 a, b)$. Since A $\beta$ deposits accumulate in the choroid plexus of $\mathrm{AD}$ patients (Dietrich et al., 2008), it is likely that $\mathrm{A} \beta$ interferes with their function. In a recent study, we have shown that mitochondrial dysfunction in choroid plexus from AD subjects occurs through a down-regulation of mitochondrial proteins and activity (Vargas et al., 2010b). In this study, the authors observed a decrease in cytochrome $c$ oxidase activity in the choroid plexus of $\mathrm{AD}$ patients. The in vitro analysis carried out in choroid plexus epithelial cells revealed a reduction in the activity of respiratory chain complex I and IV directly caused by $\mathrm{A} \beta$ exposure (Vargas et al., 2010b).

\section{OXIDATIVE STRESS AND CELL DEATH}

Oxidative damage to proteins is a relative early phenomenon in the pathogenesis of AD. A number of oxidatively damaged proteins have been reported in the hippocampus and inferior parietal lobules of cases with mild cognitive impairment and AD-related pathology corresponding to Braak stages III, IV, and V (Butterfield et al., 2006; Reed et al., 2008). In the choroid plexus on the

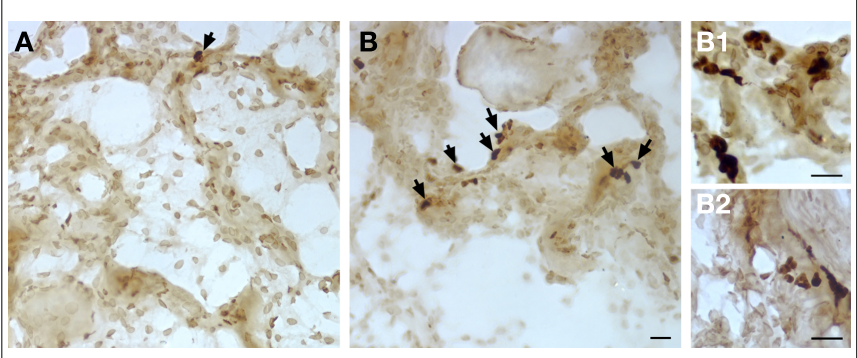

FIGURE 2 | A $\beta$ deposits (arrows) detected in choroid plexus from AD patients. (A) Choroid plexus tissue from age-matched control patient; (B) Choroid plexus from an $A D$ patient. (B1,B2) High magnification of the $A \beta$ deposits from AD patients. Scale bar $=20 \mu \mathrm{m}, n=3$ per group, $\leq 10$ fields observed from each sample. 
other hand, oxidative protein damage occurs at later stages of $\mathrm{AD}$ than in other brain areas (Perez-Gracia et al., 2009). The proteins affected by oxidation in the choroid plexus were found to be 143-3, tropomyosin, and apolipoprotein A-II. Such oxidation may result in impaired protein interactions, protein folding and protein kinase activity, abnormal function of endothelial and vascular smooth muscle cells, and impaired HDL cholesterol metabolism, thus having important implications in the deterioration of the functions of the plexus (Perez-Gracia et al., 2009).

Abnormal patterns of stress protein expression are found in the cerebral cortex and hippocampus of $\mathrm{AD}$ subjects (Anthony et al., 2003). A decreased HO-1 immunoreactivity has been observed in the $\mathrm{AD}$ choroid plexus, in agreement with suppressed HO-1 protein levels in AD CSF (Schipper et al., 2000; Anthony et al., 2003). Heat shock protein (HSP) 90, a steroid receptor chaperone, was up-regulated in the $\mathrm{AD}$ choroid plexus relative to controls, and there was a trend toward an increased expression of HSP60, a mitochondrial stress protein. This is in agreement with mitochondrial pathology recently documented in $\mathrm{AD}$ choroid plexus (Cottrell et al., 2001; Vargas et al., 2010b).

In a recent study from our group, we have described an increased nitric oxide (NO) production by the choroid plexus of $\mathrm{AD}$ patients, associated with $\mathrm{A} \beta$ deposits (Vargas et al., 2010b). A similar situation was observed in the choroid plexus of 12-monthold APP/PS1 mice, which had a noticeably high A $\beta$ expression. Excessive generation of NO has been implicated in the pathogenesis of AD (Smith et al., 1997; Aliyev et al., 2004), and plays an important role in $\mathrm{A} \beta$-induced mitochondrial dysfunction (Keil et al., 2004). The interaction between NO and cytochrome $c$ oxidase controls mitochondrial production of hydrogen peroxide, which has been shown to be implicated in cellular redox signaling (Galli et al., 2003; Carreras et al., 2004). These results, together with previous findings (Veereshwarayya et al., 2006; Petrosillo et al., 2007), support the hypothesis that $A \beta$ interferes with oxidative phosphorylation, which results in oxidative stress, and demonstrate that reactive oxygen species (ROS) generation is secondary to mitochondrial damage.

The authors also suggest that $A \beta$ is involved in cell death pathway in choroid plexus since results from our group showed that $\mathrm{A} \beta$-treated choroid plexus epithelial cells have an increased expression of caspases 3 and 9 (Vargas et al., 2010b). This finding is consistent with another study, where APP transfected cells showed a significant increase in the expression and activity of caspases 3 and 9 (Marques et al., 2003). These data suggest that the excessive generation of ROS would be responsible for initiating the apoptotic cell death process by up-regulating caspase signaling, as previously demonstrated (Takuma et al., 2005; Zhu et al., 2006).

\section{PROTEIN EXPRESSION, SYNTHESIS, AND SECRETION}

The structure and location of the choroid plexus allows it for the distribution of molecules throughout the CSF and to the brain parenchyma as well as locally. This ventricular structure possesses

\section{REFERENCES}

Aliyev, A., Seyidova, D., Rzayev, N., Obrenovich, M. E., Lamb, B. T., Chen, S. G., Smith, M. A., Perry, get in the pathogenesis of brain lesions during the development of

a multitude of specific transporters and receptors and many biologically active compounds are produced at the choroid plexus, including a large number of neuropeptides, growth factors, and cytokines (Stopa et al., 2001; Alvira-Botero and Carro, 2010). The above characteristics allow the plexus to exert a fine control over the CNS extracellular fluid, responding to changes, and maintaining baseline levels (Stopa et al., 2001).

Within the list of choroid plexus related proteins, the expression of a vast range of them is significantly diminished in $\mathrm{AD}$, including vascular endothelial growth factor (VEGF; Spuch et al., 2010), transthyretin (Sousa et al., 2007; Dietrich et al., 2008), gelsolin (Vargas et al., 2010a), apolipoprotein J (Carro et al., 2006). TTR, gelsolin and ApoJ bind brain A $\beta$, and are involved in its clearance via the endocytotic receptor megalin (Zlokovic et al., 1996; Chauhan et al., 1999; Carro et al., 2002; Antequera et al., 2009). It has also been observed that megalin expression is reduced in the choroid plexus in APP/Ps1 mice and AD patients (Dietrich et al., 2008). We suggest that $A \beta$ accumulation in the choroid plexus could disturb megalin-mediated transport and protein synthesis.

As previously reported, the choroid plexus regulates the transport of many growth factors, including brain-derived neurotrophic factor (BDNF), nerve growth factor (NGF), VEGF, insulin, and insulin-like growth factor (IGF-I). In the case of IGF-I, megalin is involved in IGF-I transport from blood into the brain, and a decrease in megalin would result in low IGFI input to the brain (Carro et al., 2005). As a consequence, the potential protective roles of IGF-I in AD would be compromised, including modulation of $\mathrm{A} \beta$ clearance, brain amyloid content, and neuroprotection against $A \beta$ toxicity (Carro and Torres-Aleman, 2004).

\section{CONCLUSION}

In this review we have proposed that choroid plexus dysfunction can be a major contributing factor to the pathology of AD. Pathogenic processes such as mitochondrial activity deficits, oxidative stress, and morphological structural changes contribute to the decreased efficacy of the choroid plexus in clearing of $A \beta$, thus resulting in an $A \beta$ accumulation in the brain. This in turn induces further pathological cascades of toxicity, inflammation, and neurodegeneration and may feedback to further enhance the disease process.

To date, the therapeutic targets have focused on diminishing the $\mathrm{A} \beta$ burden. However, we propose that targeting the upstream events such as mitochondrial deficits and oxidative stress as well as the choroid plexus carrier proteins (megalin, gelsolin) may prove to be more effective. Also, given that the choroid plexus itself has the ability to produce a nutritive "cocktail" of neurotrophic factors, there is evidence indicating that transplanted choroid plexus epithelial cells may potentially be used to protect neurons from excitotoxic damage (Emerich et al., 2004, 2005; Borlongan et al., 2008; Thanos et al., 2010).

Alzheimer's disease? Neurol. Res. 26, 547-553.

Alvira-Botero, X., and Carro, E. M. (2010). Clearance of amyloid-beta peptide across the choroid plexus in Alzheimer's disease. Curr. Aging Sci. 3, 219-229. 
Antequera, D., Vargas, T., Ugalde, C., Spuch, C., Molina, J. A., Ferrer, I., Bermejo-Pareja, F., and Carro, E. (2009). Cytoplasmic gelsolin increases mitochondrial activity and reduces Abeta burden in a mouse model of Alzheimer's disease. Neurobiol. Dis. 36, 42-50.

Anthony, S. G., Schipper, H. M., Tavares, R., Hovanesian, V., Cortez, S. C., Stopa, E. G., and Johanson, C. E. (2003). Stress protein expression in the Alzheimer-diseased choroid plexus. J. Alzheimers Dis. 5, 171-177.

Beal, M. F. (2005). Oxidative damage as an early marker of Alzheimer's disease and mild cognitive impairment. Neurobiol. Aging 26, 585-586.

Biewend, M. L., Menke, D. M., and Calamia, K. T. (2006). The spectrum of localized amyloidosis: a case series of 20 patients and review of the literature. Amyloid 13, 135-142.

Borlongan, C. V., Thanos, C. G., Skinner, S. J., Geaney, M., and Emerich, D. F. (2008). Transplants of encapsulated rat choroid plexus cells exert neuroprotection in a rodent model of Huntington's disease. Cell Transplant. 16, 987-992.

Butterfield, D. A., Poon, H. F., St Clair, D., Keller, J. N., Pierce, W. M., Klein, J. B., and Markesbery, W. R. (2006). Redox proteomics identification of oxidatively modified hippocampal proteins in mild cognitive impairment: insights into the development of Alzheimer's disease. Neurobiol. Dis. 22, 223-232.

Canevari, L., Clark, J. B., and Bates, T. E. (1999). Beta-Amyloid fragment 25-35 selectively decreases complex IV activity in isolated mitochondria. FEBS Lett. 457, 131-134.

Carreras, M. C., Converso, D. P., Lorenti, A. S., Barbich, M., Levisman, D. M., Jaitovich, A., Antico Arciuch, V. G., Galli, S., and Poderoso, J. J. (2004). Mitochondrial nitric oxide synthase drives redox signals for proliferation and quiescence in rat liver development. Hepatology 40, 157-166.

Carro, E., Spuch, C., Trejo, J. L., Antequera, D., and Torres-Aleman, I. (2005). Choroid plexus megalin is involved in neuroprotection by serum insulin-like growth factor I. J. Neurosci. 25, 10884-10893.

Carro, E., and Torres-Aleman, I. (2004). The role of insulin and insulin-like growth factor I in the molecular and cellular mechanisms underlying the pathology of Alzheimer's disease. Eur. J. Pharmacol. 490, 127-133.

Carro, E., Trejo, J. L., Gomez-Isla, T., Leroith, D., and Torres-Aleman, I. (2002). Serum insulin-like growth factor I regulates brain amyloid-beta levels. Nat. Med. 8, 1390-1397.

Carro, E., Trejo, J. L., Spuch, C., Bohl, D., Heard, J. M., and TorresAleman, I. (2006). Blockade of the insulin-like growth factor I receptor in the choroid plexus originates Alzheimer's-like neuropathology in rodents: new cues into the human disease? Neurobiol. Aging 27, 1618-1631.

Casley, C. S., Canevari, L., Land, J. M., Clark, J. B., and Sharpe, M. A. (2002a). Beta-amyloid inhibits integrated mitochondrial respiration and key enzyme activities. J. Neurochem. 80, 91-100.

Casley, C. S., Land, J. M., Sharpe, M. A., Clark, J. B., Duchen, M. R., and Canevari, L. (2002b). Beta-amyloid fragment 25-35 causes mitochondrial dysfunction in primary cortical neurons. Neurobiol. Dis. 10, 258-267.

Chauhan, V. P., Ray, I., Chauhan, A., and Wisniewski, H. M. (1999). Binding of gelsolin, a secretory protein, to amyloid beta-protein. Biochem. Biophys. Res. Commun. 258, 241-246.

Cottrell, D. A., Blakely, E. L., Johnson, M. A., Ince, P. G., and Turnbull, D. M. (2001). Mitochondrial enzymedeficient hippocampal neurons and choroidal cells in AD. Neurology 57, 260-264.

Deane, R., Wu, Z., and Zlokovic, B. V. (2004). RAGE (yin) versus LRP (yang) balance regulates Alzheimer amyloid beta-peptide clearance through transport across the blood-brain barrier. Stroke 35, 2628-2631.

Dietrich, M. O., Spuch, C., Antequera, D., Rodal, I., De Yebenes, J. G., Molina, J. A., Bermejo, F., and Carro, E. (2008). Megalin mediates the transport of leptin across the bloodCSF barrier. Neurobiol. Aging 29, 902-912.

Emerich, D. F., Skinner, S. J., Borlongan, C. V., Vasconcellos, A. V., and Thanos, C. G. (2005). The choroid plexus in the rise, fall and repair of the brain. Bioessays 27, 262-274.

Emerich, D. F., Vasconcellos, A. V., Elliott, R. B., Skinner, S. J., and Borlongan, C. V. (2004). The choroid plexus: function, pathology and therapeutic potential of its transplantation. Expert Opin. Biol. Ther. 4, 1191-1201.

Galli, S., Labato, M. I., Bal De Kier Joffe, E., Carreras, M. C., and Poderoso, J. J. (2003). Decreased mitochondrial nitric oxide synthase activity and hydrogen peroxide relate persistent tumoral proliferation to embryonic behavior. Cancer Res. 63, 6370-6377.
Gentile, M. T., Vecchione, C., Maffei, A., Aretini, A., Marino, G., Poulet, R., Capobianco, L., Selvetella, G., and Lembo, G. (2004). Mechanisms of soluble beta-amyloid impairment of endothelial function. J. Biol. Chem 279, 48135-48142.

Kalaria, R. N., Premkumar, D. R., Pax, A. B., Cohen, D. L., and Lieberburg, I. (1996). Production and increased detection of amyloid beta protein and amyloidogenic fragments in brain microvessels, meningeal vessels and choroid plexus in Alzheimer's disease. Brain Res. Mol. Brain Res. 35, 58-68.

Keil, U., Bonert, A., Marques, C. A., Scherping, I., Weyermann, J., Strosznajder, J. B., Muller-Spahn, F., Haass, C., Czech, C., Pradier, L., Muller, W. E., and Eckert, A. (2004). Amyloid beta-induced changes in nitric oxide production and mitochondrial activity lead to apoptosis. J. Biol. Chem. 279, 50310-50320.

Manczak, M., Anekonda, T. S., Henson, E., Park, B. S., Quinn, J., and Reddy, P. H. (2006). Mitochondria are a direct site of A beta accumulation in Alzheimer's disease neurons: implications for free radical generation and oxidative damage in disease progression. Hum. Mol. Genet. 15, 1437-1449.

Marques, C. A., Keil, U., Bonert, A., Steiner, B., Haass, C., Muller, W. E., and Eckert, A. (2003). Neurotoxic mechanisms caused by the Alzheimer's disease-linked Swedish amyloid precursor protein mutation: oxidative stress, caspases, and the JNK pathway. J. Biol. Chem. 278 28294-28302.

Maurizi, C. P. (2010). Choroid plexus portals, and a deficiency of melatonin can explain the neuropathology of Alzheimer's disease. Med. Hypotheses 74, 1059-1066.

Miklossy, J., Kraftsik, R., Pillevuit, O. Lepori, D., Genton, C., and Bosman, F. T. (1998). Curly fiber and tanglelike inclusions in the ependyma and choroid plexus - a pathogenetic relationship with the cortical Alzheimertype changes? J. Neuropathol. Exp. Neurol. 57, 1202-1212.

Miklossy, J., Taddei, K., Martins, R. Escher, G., Kraftsik, R., Pillevuit, O., Lepori, D., and Campiche, M. (1999). Alzheimer disease: curly fibers and tangles in organs other than brain. J. Neuropathol. Exp. Neurol. 58, 803-814.

Perez-Gracia, E., Blanco, R., Carmona, M., Carro, E., and Ferrer, I. (2009). Oxidative stress damage and oxidative stress responses in the choroid plexus in Alzheimer's disease. Acta Neuropathol. 118, 497-504.

Petrosillo, G., Portincasa, P., Grattagliano, I., Casanova, G., Matera, M., Ruggiero, F. M., Ferri, D., and Paradies, G. (2007). Mitochondrial dysfunction in rat with nonalcoholic fatty liver Involvement of complex I, reactive oxygen species and cardiolipin. Biochim. Biophys. Acta 1767, 1260-1267.

Premkumar, D. R., and Kalaria, R. N. (1996). Altered expression of amyloid beta precursor mRNAs in cerebral vessels, meninges, and choroid plexus in Alzheimer's disease. Ann. N. Y. Acad. Sci. 777, 288-292.

Preston, J. E. (2001). Ageing choroid plexus-cerebrospinal fluid system. Microsc. Res. Tech. 52, 31-37.

Reed, T., Perluigi, M., Sultana, R., Pierce, W. M., Klein, J. B., Turner, D. M., Coccia, R., Markesbery, W. R., and Butterfield, D. A. (2008). Redox proteomic identification of 4-hydroxy2-nonenal-modified brain proteins in amnestic mild cognitive impairment: insight into the role of lipid peroxidation in the progression and pathogenesis of Alzheimer's disease. Neurobiol. Dis. 30, 107-120.

Reusche, E. (1997). Argyrophilic inclusions distinct from Alzheimer neurofibrillary changes in one case of dialysis-associated encephalopathy. Acta Neuropathol. 94, 612-616.

Schipper, H. M., Chertkow, H., Mehindate, K., Frankel, D., Melmed, C., and Bergman, H. (2000). Evaluation of heme oxygenase-1 as a systemic biological marker of sporadic AD. Neurology 54, 1297-1304.

Selkoe, D. J. (2000a). The origins of Alzheimer disease: $\mathrm{a}$ is for amyloid. JAMA 283, 1615-1617.

Selkoe, D. J. (2000b). Toward a comprehensive theory for Alzheimer's disease. Hypothesis: Alzheimer's disease is caused by the cerebral accumulation and cytotoxicity of amyloid beta-protein. Ann. N. Y. Acad. Sci. 924, 17-25.

Serot, J. M., Bene, M. C., and Faure, G. C. (2003). Choroid plexus, aging of the brain, and Alzheimer's disease. Front. Biosci. 8, s515-s521.

Serot, J. M., Bene, M. C., Foliguet, B., and Faure, G. C. (1997). Altered choroid plexus basement membrane and epithelium in late-onset Alzheimer's disease: an ultrastructural study. Ann. N. Y. Acad. Sci. 826, 507-509.

Serot, J. M., Bene, M. C., Foliguet, B., and Faure, G. C. (2000). Morphological alterations of the choroid plexus in late-onset Alzheimer's disease. Acta Neuropathol. 99, 105-108. 
Smith, M. A., Richey Harris, P. L., Sayre, L. M., Beckman, J. S., and Perry, G. (1997). Widespread peroxynitritemediated damage in Alzheimer's disease. J. Neurosci. 17, 2653-2657.

Sousa, J. C., Cardoso, I., Marques, F., Saraiva, M. J., and Palha, J. A. (2007). Transthyretin and Alzheimer's disease: where in the brain? Neurobiol. Aging 28, 713-718.

Spuch, C., Antequera, D., Portero, A., Orive, G., Hernandez, R. M., Molina, J. A., Bermejo-Pareja, F., Pedraz, J. L., and Carro, E. (2010). The effect of encapsulated VEGF-secreting cells on brain amyloid load and behavioral impairment in a mouse model of Alzheimer's disease. Biomaterials 31, 5608-5618.

Stopa, E. G., Berzin, T. M., Kim, S., Song, P., Kuo-Leblanc, V., RodriguezWolf, M., Baird, A., and Johanson, C. E. (2001). Human choroid plexus growth factors: what are the implications for CSF dynamics in Alzheimer's disease? Exp. Neurol. 167, 40-47.

Takuma, K., Yao, J., Huang, J., Xu, H., Chen, X., Luddy, J., Trillat, A. C., Stern, D. M., Arancio, O., and Yan, S. S. (2005). ABAD enhances Abetainduced cell stress via mitochondrial dysfunction. FASEB J. 19, 597-598.
Tanzi, R. E., Moir, R. D., and Wagner, S. L. (2004). Clearance of Alzheimer's Abeta peptide: the many roads to perdition. Neuron 43, 605-608.

Thanos, C. G., Bintz, B., and Emerich, D. F. (2010). Microencapsulated choroid plexus epithelial cell transplants for repair of the brain. $A d v$. Exp. Med. Biol. 670, 80-91.

Valla, J., Berndt, J. D., and GonzalezLima, F. (2001). Energy hypometabolism in posterior cingulate cortex of Alzheimer's patients: superficial laminar cytochrome oxidase associated with disease duration. $J$. Neurosci. 21, 4923-4930.

Vargas, T., Antequera, D., Ugalde, C., Spuch, C., and Carro, E. (2010a). Gelsolin restores A beta-induced alterations in choroid plexus epithelium. J. Biomed. Biotechnol. 2010, 805405.

Vargas, T., Ugalde, C., Spuch, C., Antequera, D., Moran, M. J., Martin, M. A., Ferrer, I., Bermejo-Pareja, F., and Carro, E. (2010b). Abeta accumulation in choroid plexus is associated with mitochondrialinduced apoptosis. Neurobiol. Aging 31, 1569-1581.

Veereshwarayya, V., Kumar, P., Rosen, K. M., Mestril, R., and Querfurth, H. W. (2006). Differential effects of mitochondrial heat shock protein 60 and related molecular chaperones to prevent intracellular beta-amyloidinduced inhibition of complex IV and limit apoptosis. J. Biol. Chem. 281, 29468-29478.

Weller, R. O. (1998). Pathology of cerebrospinal fluid and interstitial fluid of the CNS: significance for Alzheimer disease, prion disorders and multiple sclerosis. J. Neuropathol. Exp. Neurol. 57, 885-894.

Wen, G. Y., Wisniewski, H. M., and Kascsak, R. J. (1999). Biondi ring tangles in the choroid plexus of Alzheimer's disease and normal aging brains: a quantitative study. Brain Res. 832 , 40-46.

Zhu, Y., Hoell, P., Ahlemeyer, B., and Krieglstein, J. (2006). PTEN: a crucial mediator of mitochondriadependent apoptosis. Apoptosis 11, 197-207.

Zlokovic, B. V. (2004). Clearing amyloid through the blood-brain barrier. $J$. Neurochem. 89, 807-811.

Zlokovic, B. V., Martel, C. L., Matsubara, E., Mccomb, J. G., Zheng, G., Mccluskey, R. T., Frangione, B., and Ghiso, J. (1996). Glycoprotein 330/megalin: probable role in receptor-mediated transport of apolipoprotein $\mathrm{J}$ alone and in a complex with Alzheimer disease amyloid beta at the blood-brain and blood-cerebrospinal fluid barriers. Proc. Natl. Acad. Sci. U.S.A. 93, 4229-4234.

Conflict of Interest Statement: The authors declare that the research was conducted in the absence of any commercial or financial relationships that could be construed as a potential conflict of interest.

Received: 10 January 2012; accepted: 10 April 2012; published online: 03 May 2012.

Citation: Krzyzanowska A and Carro E (2012) Pathological alteration in the choroid plexus of Alzheimer's disease: implication for new therapy approaches. Front. Pharmacol. 3:75. doi: 10.3389/fphar.2012.00075

This article was submitted to Frontiers in Neuropharmacology, a specialty of Frontiers in Pharmacology.

Copyright (c) 2012 Krzyzanowska and Carro. This is an open-access article distributed under the terms of the Creative Commons Attribution Non Commercial License, which permits noncommercial use, distribution, and reproduction in other forums, provided the original authors and source are credited. 